\title{
ИННОВАЦИОННОЕ РАЗВИТИЕ КАК БЫСТРОЕ РЕАГИРОВАНИЕ НА ПОТРЕБНОСТИ ОБЩЕСТВА И БИЗНЕСА
}

\author{
(c) 2020 Кучерявенко Дмитрий Михайлович
}

кандидат экономических наук, доцент, кафедра «Экономика и управление организацией» Самарский государственный технический университет (СамГТУ), Россия, Самара

В статье рассматриваются инновации как оперативный ответ на потребности общества или те проблемы, которые в первую очередь стоят перед странами мира. Поднимается вопрос о важности инноваций, рассматриваются наиболее перспективные направления инновационного развития промышленного сектора. Дана характеристика аддитивного производства как элемента, при котором компании в глобальной цепочке создания базовой ценности продукта быстрее реагируют на появление новых рынков с более дешевыми операторами и производят законченные сложные продукты и бизнес-процессы. Предметом исследования является инновация. Объектом исследования выступает инновации в промышленном секторе и медицине. Степень разработки находится на уровне теоретического и практического применения. Были рассмотрены работы ведущих специалистов в области инновационного развития и разработок, так как: Бузулукина Е. М., Шаповалов А.А., Николаев А. И. и другие.

Было выявлено, что новые технологии в сочетании с инновационными бизнес-моделями предлагают производителям различные возможности для повышения их ценностного предложения, особенно малым и средним предприятиям. Было также выявлено, что инновации в производстве гарантируют особое влияние на все аспекты производственного процесса: от проектирования, исследований и разработок производственного цикла, управления цепочками поставок и логистики до продаж, маркетинга и даже управления окончанием срока службы. Были рассмотрены примеры наборов диагностических, образовательных и учебных инструментов и материалов, к которым МСП смогут получить простой доступ для анализа и устранения недочетов в технологиях и знаниях.

Было доказано, что виртуальная реальность позволяет людям обучаться в средах и ситуациях, которые на текущий момент либо не существуют, либо иным образом трудно проектируемы в жизни. Было выявлено, что существует достоверный экспресс-тест, который позволяет обнаружить виpyc COVID-19 менее чем за 15 минут и, таким образом, значительно сократить время обработки, а также улучшить отслеживание контактов, что оказывает благоприятное влияние на общество в борьбе с недугом.

Ключевые слова: инновации, инновационное развитие, потребности, общество, инновационные разработки, аддитивное производство, виртуальная реальность, автоматизация.

Инновации в современном мире становятся не просто новшеством или модным словом, они выступают необходимостью с целью улучшения функционирования бизнеса, налаживания внутренних и внешних деловых связей, коммуникаций и бизнес - процессов. Общество диктует изменения в силу своего быстрого развития и активного обмена опытом с зарубежными странами для инновационного роста [1].

У инноваций существует множество определений. Это, прежде всего, новые продукты, процессы и бизнес-модели, которые обеспечивают коммерческую ценность и стимулируют возможности роста бизнеса. Огромное значение инновации имеют для производственного сек- тора, в котором создаются материальные блага общества, которые удовлетворяют базовые потребности общества и нацелены на повышение уровня его благосостояния [2].

Инновации в производстве гарантируют особое влияние на все аспекты производственного процесса: от проектирования, исследований и разработок производственного цикла, управления цепочками поставок и логистики до продаж, маркетинга и даже управления окончанием срока службы [3]. Эти инновации позволят создать высокоинтеллектуальные, информационные предприятия и такие бизнес-модели, которые могут быстро реагировать на изменения и предоставлять совершенно новые индивиду- 
ализированные интеллектуальные продукты и услуги [4].

Будущее современного производства определенно за цифровыми технологиями. Новые технологии в сочетании с инновационными бизнес-моделями предлагают производителям различные возможности для повышения их ценностного предложения, особенно малым и средним предприятиям (МСП) [5].

Существующая программа промышленной трансформации ориентирована на инновации в производстве, основанные на цифровых технологиях и данных искусственного интеллекта, развитие лидерских качеств и ускорение внедрения инструментов и дисциплин Индустрии 4.0. На практике компания «IMCRC», которая является ведущей научно-исследовательской организацией, в партнерстве с ключевыми отраслевыми компаниями, такими как Ai Group, Advanced Manufacturing Growth Center, CSIRO, a также при участии международных организаций, таких как Институты Фраунгофера, разрабатывает набор диагностических, образовательных и учебных инструментов и материалов, к которым МСП смогут получить простой доступ для анализа и устранения недочетов в технологиях и знаниях.

Ключевым компонентом данной программы является создание национальной сети демонстраторов, таких как университетские жилые лаборатории и промышленные образцы, с помощью которых МСП могут ощутить практические преимущества передовых производственных технологий, материалов и информационных систем. Программа промышленной трансформации интегрируется с более широкими исследовательскими проектами, обеспечивая их трансформационное воздействие. Это требуется для того, чтобы в исследовательских проектах участвовали компании, внедряющие инновации не только в своих технологиях, но и в цифровых и бизнес-моделях.

Особое внимание сегодня уделяется аддитивному производству, или 3D-печати, которая является самым быстрорастущим сектором производства в мире благодаря множеству преимуществ, которые он предлагает компаниям с точки зрения разработки новых продуктов, времени выхода на рынок, сокращения отходов и стоимости продукта [6].

Аддитивное производство позволяет разрабатывать и производить законченные слож- ные продукты и связанные с ними передовые бизнес-модели, такие как процессы проектирования под руководством заказчика и совершать производство точно в срок [7]. Под влиянием глобализации аддитивное производство влияет на то, как компании в глобальной цепочке создания базовой ценности продукта реагируют на появление новых рынков с более дешевыми операторами [8]. На этом фоне компании, например, в Австралии, сейчас начинают исследовать и внедрять аддитивные технологии в свои операции, чтобы дополнить существующие процессы проектирования и производства.

Чтобы еще больше ускорить этот процесс, «IMCRC» запрашивает отзывы клиентов отрасли о своем восприятии аддитивной технологии, а также о возможностях и проблемах ее внедрения. После чего создается карта отзывов, на основе которых корректируются предложения компании, основываясь на предпочтениях и спросе на свои продукты [10].

Доступной в настоящее время промышленной автоматизации не хватает гибкости, поскольку она предназначена для крупномасштабных процессов с небольшими вариациями и является экономически невыгодной для многих малых и средних предприятий (МСП) [9]. В таком случае компании прибегают к вспомогательным роботам, которые взаимодействуют совместно с людьми и друг с другом, чтобы улучшить способности восприятия, осведомленности и принятия решений, обеспечивая полную автономию и самообучающееся поведение.

В результате появляются усовершенствованные материалы, которые выступают новыми или модифицированными материалами для обеспечения превосходных характеристик, повышая прочность, вес и компоновку. Это может быть «проактивно» интегрировано на ранней стадии проектирования, чтобы предложить множество новых атрибутов, таких как биосовместимость, биоразлагаемость, энергоэффективность и самовосстановление. Применяемые по всей цепочке создания стоимости, датчики и аналитика данных включают профилактическое обслуживание, логистическое отслеживание для повышения операционной эффективности, контроль качества и предложения услуг при интеграции в конечный продукт.

Еще одним ключевым инновационным продуктом является постоянно меняющаяся дополненная и виртуальная реальность. Она может 
использоваться для наложения дизайна продукта на среду конечного использования, оптимизации настроек машин в виртуальном мире, облегчения удаленного сотрудничества и обучения или руководства работниками через сложные задачи.

Виртуальная реальность позволяет людям обучаться в средах и ситуациях, которые на текущий момент либо не существуют, либо иным образом трудно проектируемы в жизни. Это могут быть тренинги по электробезопасности и аварийно-спасательным работам при низковольтном оборудовании. Но, тем не менее, одна из основных проблем на пути к более широкому внедрению обучения виртуальной реальности является невозможность обеспечения необходимым для эффективного обучения физическим и тактильное взаимодействием, которое повышение качество и эффективность данного обучения. Поэтому сегодня с помощью готовых технологий виртуальной реальности до конца нельзя достичь полного понимания, как, например, безопасно вывести из опасной ситуации коллегу, которого может поразить электрическим током.

В сотрудничестве с Университетом Дикина компания «Melbourne Water» будет продвигать применение виртуальной реальности для обучения и повышения безопасности нынешних и будущих работников электротехнической промышленности. В течение следующих двух лет исследовательская группа во главе с доцентом Беном Хораном разработает новый симулятор электробезопасности, в котором будут применены передовые алгоритмы робототехники и управления для создания сценариев обучения, соответствующих нагрузкам и нагрузкам при проведении операций по спасению. Например, чтобы эффективно моделировать физические взаимодействия, необходимые для отвода коллеги, пострадавшего от поражения электрическим током, исследователь будет сотрудничать с поставщиками услуг обучения и другими заинтересованными сторонами в космосе, чтобы лучше понять их потребности в обучении по вопросам здоровья и безопасности [10].

Проект предлагает новый и инновационный способ проведения тренинга по безопасности и спасанию, сокращая, с одной стороны, потребность в специализированных инструкторах и вариативность обучения между инструкторами, и предлагая, с другой стороны, высококачествен- ное и легко доступное обучение по более низкой цене.

Уже несколько лет работают над расширением границ по технологиям низкоуглеродистого бетона. Обычный портландцемент (OPC) является основным связующим для бетона и вторым по величине источником выбросов углерода после ископаемого топлива. Заменив 50\% содержания ОРС в своем бетоне дополнительными вяжущими материалами (SCM), такими как измельченный гранулированный доменный флаг (GGBFS) в качестве связующего, «Boral» создал бетон с низким содержанием углерода, который работает как обычный бетон. Тем не менее, существует значительный потенциал для увеличения доли замены ОРС и дальнейшего расширения границ с низким содержанием углерода [10].

В сотрудничестве с Сиднейским технологическим университетом (UTS) и Southern Highland Concrete Construction компания Boral разработает передовые технологии для производства, укладки и выдержки нового сверхустойчивого бетона. Целью двухлетнего исследовательского проекта является производство и испытание нового сверхустойчивого бетона с повышенным содержанием, вяжущего до 70\% SMC [10].

Исследователи из UTS Boral Center for Sustainable Building в UTS Tech Lab будут оценивать эффективность предлагаемых производственных подходов для решения проблемы повышения прочности и улучшения методов обработки поверхности. После лабораторных испытаний низкоуглеродистый бетон будет испытан на строительных площадках, чтобы убедиться, что он соответствует промышленным требованиям к технологичности, долговечности и прочности. Это делается также для решения вопросов выброса углекислого газа в атмосферу в рамках 17 целей устойчивого развития планеты. До 2050 года поставлена задача уменьшить его количество, с помощью отлаженных действий всех участников процесса (государство, бизнес, инженеры, подрядчики, общество в целом).

Другим ответом на потребность общества стало тестирование - жизненно важного компонента в борьбе с распространением COVID-19. Для обнаружения вируса обычно используются ПЦР (полимеразная цепная реакция). Помимо того, что для тестирования образца требуется специализированное лабораторное оборудование и обученные ученые, для проведения 
ПЦР-тестов требуется несколько часов.

«Alcolizer» стремится разработать экономически эффективный тест на COVID -19 в пунктах оказания медицинской помощи с использованием существующего приложения для тестирования наркотиков, который может обнаружить вирус менее чем за 15 минут и, таким образом, значительно сократить время обработки, а также улучшить отслеживание контактов.

В сотрудничестве с Сиднейским технологическим университетом (UTS) компания «Alcolizer Technology» разрабатывает прототип для экспресс-теста слюны на антигены вируса SARS-CoV-2. Используя систему тестирования на наркотики Alcolizer (Druglizer LE5), тест будет собирать слюну в картридж, помещенный в существующее портативное устройство. Благодаря адаптации технологии iStrip устройство сможет напрямую измерять вирусную нагрузку в образце слюны и отображать результат на небольшом экране прибора. Благодаря включенному GPS и подключению к облачным инструментам отчетности, устройство также поможет властям в отслеживании контактов.

Проект направлен на продвижение дизайна и тестирования прототипа, чтобы ускорить его коммерциализацию. Сотрудничая со специализированными фирмами по промышленному дизайну и специалистами по электронике, команда проекта также окажет помощь в адаптации полностью автоматизированного завода по производству роботов Alcolizer в Балкатте.

Также серьезно поднят вопрос о хронических заболеваниях, такие как диабет 2 типа, которые являются основными причинами смерти и инвалидности во всем мире. Позволяя людям делать лучший выбор образа жизни с помощью персонализированного интеллектуального пластыря, который измеряет биомаркеры и отслеживает реакцию организма на еду, «Nutromics» стремится снизить факторы риска хронических заболеваний и создать новую модель предотвратимого медицинского обслуживания. «Nutromics» сотрудничает с Университетом Гриффита, Университетом RMIT и Romar Engineering, чтобы завершить разработку технологии и разработать экономичный производственный процесс для производства носимых смарт-пластырей.

В течение двух лет исследователи объединят ряд технологий, включая микроиглы, микрофлюидику и мягкую электронику. Используя печать с рулона на рулон (R2R), смарт-заплатку можно массово и с высокой скоростью производить автоматизированные системы с минимальным участием человека, при этом используется большая площадь носителя использования. Результаты исследования внесут свой вклад в разработку умного патча и движка ИИ с глубоким обучением для создания носимого устройства, предназначенного для выявления позитивных изменений образа жизни, необходимых для улучшения здоровья и снижения риска хронических заболеваний, связанных с образом жизни, таких как диабет 2 типа.

Таким образом, инновации - это неотъемлемый шаг развития общества, которое находится в постоянном развитии. Промышленный сектор особенно внедряет инновации для оптимизации процессов [13]. В данном случае используется аддитивное производство, которое позволяет разрабатывать и производить законченные сложные продукты, что приводит к дополнению существующих процессов проектирования и производства. В результате промышленной автоматизации, после внедрения вспомогательных роботов, появляются усовершенствованные материалы, которые выступают новыми или модифицированными материалами для обеспечения превосходных характеристик.

Проблемы экологии и безопасности жизни общества всегда стояли перед ведущими странами мира, борьба с COVID-19 привела к разработке экспресс-теста с использованием слюны на антигены вируса SARS-CoV-2. То есть принцип взаимодействия инновации и общества заключается в следующем: у общества появляется конкретный запрос (проблема) - начинается инновационная разработка, способная ее разрешить, - апробация инновации в жизни общества, которая позволяет повышать уровень благосостояния общества и конкурентоспособность бизнеса в той или иной стране и за ее пределами.

\section{Библиографический список}

1. Алпеева Т.А. Перспективы инновационного развития организаций // Молодой ученый. 2016. № 1 . С. 289292.

2. Бузулукина E.M., Шаповалов А.А. Выбор и обоснование инновационной стратегии [Электронный ресурс]. URL: http://www.rae.ru/forum2012/21/2987 (дата обращения: 29.12.2020). 
3. Елецких Г.Г. Развитие инновационных систем: проблемы и перспективы современной России // Вопросы инновационной экономики. 2015. Т. 5, № 4. doi: 10.18334/ тес.5.4.2105

4. Кузнецов, Б. Т. Инновационный менеджмент: Учебное пособие / Б. Т. Кузнецов, А. Б. Кузнецов. // М.: Юнити. 2016. С. 367.

5. Мезенина E. В. Инновационная стратегия развития организации // Инновационная Росссия; Модернизация, Инновации, Развитие. URL: http://econf.rae.ru/article/6533 (дата обращения: 29.12.2020).

6. Мухамедьяров, А. М. Инновационный менеджмент: Учебное пособие / А. М. Мухамедьяров, Э. А. Диваева. // М.: Инфра-М. 2019. С.192.

7. Николаев А.И. Инновационное развитие и инновационная культура // Электронный pecypc: http://www. center-inno.ru/materials/library/04-4 (дата обращения: 29.12.2020).

8. Семенова, А.А. Инновационный менеджмент / А. А. Семенова, М. Н. Кузина. // М.: Русайнс. 2017. С. 240.

9. Соколова, О.Н. Инновационный менеджмент / О.Н. Соколова. // М.: КноРус. 2018. С. 64.

10. Официальный сайт «IMCRC» https://www.imcrc.org/case-studies/ (дата обращения: 29.12.2020).

11. Сураева M. О. Развитие компенсационных систем в сфере регулирования трудовых отношений через инструменты менеджмента //Экономика и бизнес: управление экономическими системами.2015. С. 1-13.

12. Сураева М. О. Инновационное развитие предприятий промышленного комплекса // Экономика и управление. № 1(11).2020. С. 66-69.

13. Суржиков М.А. Формирование инновационной стратегии на предприятии // Вестник Адыгейского государственного университета. Серия 5: Экономика. 2016. № 2 (180). URL: https://cyberleninka.ru/article/n/ formirovanie-innovatsionnoy-strategii-na-predpriyatii. (дата обращения: 29.12.2020). 